\title{
The Impact of an Educational Program on Enhancing Knowledge towards Drug Addiction among Health Care Providers in Saudi Arabia
}

\author{
By Najla J. Alhraiwil", Razan A. AlYoussef , Nora K. AlShlash ${ }^{*}$, \\ Samar A. Amer ${ }^{\S}$, Nashwa M. Radwan ${ }^{* *}$, Ali M. Al Hazmi ${ }^{\dagger+}$, \\ Walid A. Al-Shroby ${ }^{H+}$ Fahad A. AlAmri ${ }^{\S \S}$
}

Drug addiction is a major preventable and treatable problem. One important way of reducing drug abuse is through provision of effective and accurate information about drug addiction to health care providers $(\mathrm{HCPs})$ to enable them to detect suspected cases earlier and provide them with the help they need. This study aimed to assess health care providers' knowledge related to drug addiction and availability of related national health services and the impact of an educational program intervention on the perceived knowledge. An interventional longitudinal study was conducted in Saudi Arabia between 10 Dec. 2017 and 4 Jan. 2018. The study included 383 participants HCPs aged 20-60 years old. They were randomly selected using a stratified sampling technique out of 143,517 HCPs who attended an educational program organized by the General Directorate for Clinical Education, Ministry of Health, in collaboration with the National Committee for Narcotics Control. A pre-designed questionnaire was used to collect data from the participants before and after attending the program. The study recorded a relatively good baseline level of knowledge about drug addiction among participating HCPs (average knowledge score 9.54 3.7 out of 13) with no significant difference between genders, occupations or education levels. At the same time, the study reported a fair level of knowledge regarding available national health services for drug addiction (Nebras). After the educational program, the drug addiction knowledge score improved from $9.54 \pm 3.7$ to $11.15 \pm 2.9$ with a statistically significant difference (mean difference $2.7 \pm 1.3, t=2.83, P=.01)$. Morover, the knowledge score about the available national service (Nebras) showed also a statistically significant improvement (mean difference 54.1 \pm 15.6 , range: 7-93, $P=.00)$. Although many HCPs lack formal training regarding drug addiction, providing them with a short educational intervention can be effective, and has the potential to improve service utilization.

Keywords: Drug addiction, Educational program, Health care providers, Knowledge, Saudi Arabia

\section{Introduction}

The full impact and societal cost of drug abuse and addiction are considerable; however, there are a number of useful indicators that can give us insight into its true impact. Such measures include monitoring of reported adverse

\footnotetext{
*Public Health Specialist, Head, Ministry of Health, Kingdom of Saudi Arabia.

${ }^{\dagger}$ Health Education Specialist, Ministry of Health, Kingdom of Saudi Arabia.

${ }^{*}$ Health Promotion Specialist, Ministry of Health, Kingdom of Saudi Arabia.

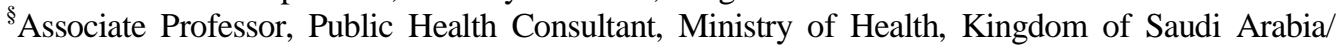
Zagazig University, Egypt/ Royal College of General Practitioners, UK.

**Associate Professor, Public Health Consultant, Ministry of Health, Kingdom of Saudi Arabia/ Tanta University, Egypt.

${ }^{\dagger}$ Associate Professor, King Saud University, Kingdom of Saudi Arabia.

${ }^{+}$Lecturer, Public Health Consultant, Ministry of Health, Kingdom of Saudi Arabia/Beni-Suef University, Egypt.

${ }^{\S}$ Family Physician, Director General, Ministry of Health, Saudi Arabia.
} 
health effects, which in turn may be used to estimate the financial cost of treatment for drug addiction and associated disorders, as well as providing a qualitative measure of premature mortality and morbidity (Wallace and Kohatsu 2007). Besides costs that arise from lost productivity of the affected individual as well as family members or caregivers, potential crimes committed to sustain the addictive habit, and the provision of rehabilitative social welfare programs, the severity of the increased risk of contracting human immune deficiency virus (HIV) associated with intravenous drug use (Cassens 1992) and the consequent public health concern this poses cannot be understated. Overall, according to the World Health Organization, the global burden of disease attributable to alcohol and illicit drug use is $5.4 \%$ of the total burden of disease (World Health Organization 2010).

In the Arab world in general, and Islamic countries in particular, possession of any kind of addictive substance is illegal, and alcohol and substance use are forbidden. Even in those Arab countries where alcohol is tolerated, the strong societal stigma surrounding substance use is a major impediment to those wishing to seek help for addiction, and from a health service perspective, it constitutes a barrier to reporting, early detection and treatment. Thankfully, part of the new vision for Saudi Arabia includes a commitment to a more accepting and supportive community and a willingness to openly address previously stigmatized issues. Consequently, the National Committee for Narcotics Control (NCNC) established "Nebras": a free health service that provides advice and support for people struggling with drug addiction and their families in Saudi Arabia, as well as operating a hotline where drug addicts reported completely private and confidential in order to avail them of the specialized help that they need (National Center for Narcotics Control 2018).

One important way of reducing the use of drugs among adolescents is through providing them with reliable, accessible, and well-presented information on the subject. Providing people with accurate information on any healthrelated matter affords them the ability to make informed decisions in that regard (Wright and Pearl 2000). An essential prerequisite for the creation of any such materials is the assessment of existing health-related knowledge among the intended target population, as this facilitates the formulation of effective preventive programs (McBride 2003).

It is essential, therefore, that the health professionals who are sought out as a source of advice about health issues in general, and drug addiction issues in particular, are themselves knowledgeable about the risk factors, warning signs, and social, psychiatric, and medical sequelae of drug addiction, as well as being aware of the available services to whom they can refer their patients or concerned family members (US Department of Health and Human Services 2016). Only a handful of studies on drug addiction awareness among the Saudi population have been published, none of which have focused on the perspective of Health Care Providers (HCPs).

This study aimed to assess health care providers' knowledge related to drug addiction and availability of related national health services and the impact of an educational program intervention on the perceived knowledge. 


\section{Methodology}

A prospective longitudinal interventional study was conducted in Saudi Arabia on various healthcare providers between 10 December 2017 and 4 January 2018 to assess their pre- and post-knowledge towards drug addiction via questionnaire before and after an educational program.

\section{Study Population}

In brief, the educational program consisted of a train-the-trainer format for selected coordinators from each region, followed by didactic lectures conducted by these trainers in their regions along with dissemination of supporting educational handouts. It targeted $70 \%$ of Ministry of Health $(\mathrm{MoH})$ employees from all 20 health regions in Saudi Arabia, including employees of all specialties (medical and non-medical) and all nationalities, from regional health affairs directorates, hospitals, and primary health care centres. The study included 383 participants (288 males and 95 females) aged 20-60 years old. They were randomly selected by using a stratified sampling technique out of 143,517 HCPs who attended the educational program organized by the General Directorate for Clinical Education, $\mathrm{MoH}$, in collaboration with the NCNC. The sample was first stratified according to the Saudi 20 health regions and then the subjects were randomly collected from each region. The calculated sample size was 300 by using epi-info program and it was hypothesized that the knowledge prior to attending the educational program was about $40 \%$, and this was expected to increase to about $70 \%$ after completion of the program with a $95 \%$ confidence interval and $80 \%$ power. The final sample size was adjusted for expected attrition rate $(20 \%)$, therefore, the final sample size was equal to 360 .

\section{The Study Instrument}

A comprehensive self-report questionnaire was designed to collect data from the participants pre and 3-weeks post attending the educational program. The questionnaire was distributed to $500 \mathrm{HCPs}$ before and after their participation in the educational program and the response rate was $76.60 \%$ (Four regions were excluded from the study as they did not return the questionnaire). The total sample was 383 participants. The questionnaire was provided to the program delivery team to be reviewed for content relevance and comprehensiveness, and further reviewed by a panel of public health experts for content validity, accuracy, and clarity of different items, which included:

1. Socio-demographic data including age, sex, occupation, education, nationality, region.

2. Data about participants' knowledge regarding signs and negative health consequences of drug addiction, as well as their awareness about the NCNC Program, Nebras, and its free telephone hotline. 
3. A knowledge score was developed giving each correct item one point and zero points for each incorrect one. The total score for each participant's knowledge about drug addiction (0-13 points) and the Nebras service (0-4 points), as well the mean change in knowledge score, were calculated pre- and post-training.

\section{Ethical Considerations}

Ethical approval for the study was granted from the Institutional Review Board at King Fahad Medical City, Riyadh, Saudi Arabia through the relevant $\mathrm{MoH}$ health authorities. Consent was obtained from each participating HCP after explaining the nature and benefit of participation.

\section{Statistical Analysis}

Data entry and analysis was performed using the Statistical Package for Social Sciences (SPSS, version 16). Mean, median, the percentage of change and ranges were used for quantitative data summarization, while for their analysis; Paired -ttest and Wilcoxon signed rank test were used. Numbers (frequency) and percentage were used for qualitative data summarization. MC-Nemar and Fisher exact test were used to analyze statistical significance. Differences were considered statistically significant when the p-value was less than .05.

\section{Results}

Concerning the geographic distribution of the participating HCPs, four out of the total twenty health care regions in the Kingdom were excluded as their questionnaire response rate was zero. The highest response rate was from Najran region (10.44\%) followed by the Northern Borders region and Riyadh region $(9.92 \%$ and $9.40 \%$, respectively). Nearly half $(45.16 \%)$ of the participants in the training program work in hospitals, while $28.72 \%$ work in regional Health Affairs General Directorates and $26.10 \%$ work in PHCs. A possible explanation for the higher response rate among HCPs working in hospitals compared to primary health centers may be the relatively higher work load of HCPs in primary care preventing their participation (Table 1).

Table 1 presents the socio-demographic characteristics of the participating HCPs. About half (48.56\%) of them were aged 30-40 years old, and about three quarters were males with technical occupations who were university educated $(78,85 \%, 75.20 \%$ and $73.10 \%$, respectively). 
Table 1. Socio-Demographic Characteristics among Studied Health Care Providers

\begin{tabular}{|l|c|c|}
\hline Characteristics & Number $\mathbf{( N = 3 8 3 )}$ & Percent (\%) \\
\hline Age groups: & 81 & 21.15 \\
$20-30$ & 186 & 48.56 \\
$30-40$ & 98 & 25.59 \\
$40-50$ & 18 & 4.70 \\
$50-60$ & & \\
\hline Sex: & 95 & 24.80 \\
\hline Female & 288 & 75.20 \\
Male & 81 & 21.15 \\
\hline Occupation: & 302 & 78.85 \\
\hline Administrative & & \\
Technical & 4 & 1.04 \\
\hline Education: & 64 & 16.71 \\
Intermediate & 280 & 73.10 \\
Secondary & 26 & 6.78 \\
Undergraduate & & \\
Postgraduate & 110 & 28.72 \\
\hline Work location: & 173 & 45.16 \\
Regional health affairs & 100 & 26.10 \\
Hospitals & & \\
PHC centers & & \\
\hline Missing & & \\
\hline
\end{tabular}

*Missing data=9.

Improvement of knowledge levels regarding negative health consequences of drug addiction was shown in Table 2. Psychological disorders and behavioral disorders were the most commonly known negative health consequences reported by more than ninety percent of HCPs (98.62\% and $90.86 \%$, respectively). Statistically significant differences were recorded regarding all negative health consequences before and after the educational program $(\mathrm{p}<.05)$.

Table 2. Pre- and Post-Program Knowledge Regarding Negative Health Consequences of Drug Addiction

\begin{tabular}{|l|c|c|c|}
\hline Negative Health Consequences & $\begin{array}{c}\text { Pre-program } \\
\mathbf{N = 3 8 3}\end{array}$ & $\begin{array}{c}\text { Post-program } \\
\mathbf{N = 3 8 3}\end{array}$ & P-value \\
\hline & $\mathbf{N}(\mathbf{\%})$ & $\mathbf{N}(\mathbf{\%})$ & \\
\hline Cardiovascular disease & $198(51.7)$ & $226(59.01)$ & .00 \\
\hline Gastrointestinal disease & $175(45.69)$ & $254(66.32)$ & .00 \\
\hline Liver cirrhosis & $221(57.7)$ & $274(71.54)$ & .001 \\
\hline Psychological disorder & $336(87.73)$ & $358(98.62)$ & .01 \\
\hline Behavioral disorder & $318(83.03)$ & $348(90.86)$ & .02 \\
\hline Involvement in crimes & $301(78.6)$ & $320(83.55)$ & .00 \\
\hline
\end{tabular}

Table 3 shows that more than ninety percent (respectively $91.38 \%, 90.86 \%$ and $91.91 \%$ ) of the studied HCPs recorded post-program knowledge about drug addiction signs concerning continual absence from home, behavioral changes and physical body signs. Improvement in knowledge levels after the program 
regarding all items of drug addiction signs was evident with statistically significant differences $(\mathrm{P}<.05)$.

Table 3. Pre- and Post-Program Knowledge Regarding Drug Addiction Signs

\begin{tabular}{|l|c|c|c|}
\hline Drug Addiction Signs & $\begin{array}{c}\text { Pre-program } \\
\mathbf{N = 3 8 3}\end{array}$ & $\begin{array}{c}\text { Post-program } \\
\mathbf{N = 3 8 3}\end{array}$ & P-value \\
\hline Sleep problems & $\mathbf{N}(\boldsymbol{\%})$ & $\mathbf{N}(\mathbf{\%})$ & \\
\hline Neglecting religious rituals & $289(77.81)$ & $324(84.6)$ & .05 \\
\hline Continual absence from home & $305(77.81)$ & $336(87.73)$ & .003 \\
\hline Behavioral changes & $301(78.59)$ & $350(91.38)$ & .00 \\
\hline Financial troubles & $312(81.46)$ & $348(90.86)$ & .02 \\
\hline Physical body signs & $295(77.02)$ & $342(89.3)$ & .00 \\
\hline Neglecting general appearance & $290(75.72)$ & $352(91.91)$ & .00 \\
\hline
\end{tabular}

Pre- and post-program knowledge of the studied HCPs regarding Nebras program is presented in Table 4. It is evident from the table that before the educational program, more than half of the participating HCPs did not know about the availability of the government health service for drug addicts nor the availability of a hotline for informing about drug addicts $(57.96 \%$ and $65.01 \%$, respectively). This was compared to more than three quarters of them who recorded positive knowledge regarding the same items after the educational program $(89.89 \%$ and $78.72 \%$, respectively) $(\mathrm{P}<.05)$.

Table 4. Pre and Post-Program Knowledge Concerning Nebras Program

\begin{tabular}{|c|c|c|c|}
\hline Knowledge & $\begin{array}{c}\text { Pre-program } \\
\mathbf{N}=383\end{array}$ & $\begin{array}{c}\text { Post-program } \\
\text { N=376 }\end{array}$ & P-value \\
\hline \multicolumn{4}{|c|}{ There is a national program for drug addiction } \\
\hline & $\mathbf{N}(\%)$ & $\mathbf{N}(\%)$ & \\
\hline No & $3(0.78)$ & $0.0(0)$ & .00 \\
\hline Yes & $158(41.25)$ & $338(89.89)$ & .00 \\
\hline I don't know & $222(57.96)$ & $38(10.11)$ & .00 \\
\hline \multicolumn{4}{|c|}{ There is a free drug addiction hotline } \\
\hline No & $6(1.57)$ & $3(0.79)$ & .89 \\
\hline Yes & $128(33.42)$ & $296(78.72)$ & .00 \\
\hline I don't know & $249(65.01)$ & $77(20.48)$ & .09 \\
\hline \multicolumn{4}{|c|}{ If yes, do you know the name of the program that provides it? } \\
\hline No & $3(2.34) \AA^{1}$ & $42(14.19) \AA^{2}$ & .03 \\
\hline Yes & $125(97.66)$ & $254(85.81)$ & .05 \\
\hline \multicolumn{4}{|c|}{ Able to correctly name the program } \\
\hline No & $94(75.2) \AA^{3}$ & $194(79.18) \AA^{4}$ & \multirow{2}{*}{.08} \\
\hline Yes & $31(24.8)$ & $60(24.49)$ & \\
\hline
\end{tabular}

$\circledR 1: \mathrm{n}=128, \AA 2: \mathrm{n}=296,{ }^{\circledR} 3: \mathrm{n}=125, \AA^{4} \mathrm{n}=254$

The number of participants who reported that they know the name of the program, that provides the drug addiction hotline, doubled after attending the educational activity $(\mathrm{P}<.05)$; however, only $(24 \%)$ out of these participants -who 
thought they knew the name of the program- were able to recall the correct name (Nebras) after attending the educational program.

The knowledge score regarding drug addiction among studied HCPs changed from $9.54 \pm 3.7$ to $11.15 \pm 2.9$ after the program with a statistically significant difference (mean difference $=2.7 \pm 1.3, \mathrm{t}=2.83, \mathrm{P}=.01$ ). While the mean difference in the knowledge score for Nebras was $54.1 \% \pm 15.6 \%$, range $7 \%-93 \%$.

\section{Discussion}

In Saudi Arabia, as with other Arab communities, denial and shame constitute the biggest barriers to increased awareness of drug abuse and addiction; nonetheless, given the dire consequences of inaction, we cannot allow this to stand in the way of effective prevention, support, and rehabilitation for those affected. The first step in breaking the social stigma that prevents people getting help is to bring this dialogue into the public domain, and to do this effectively, we need to form a clear and directed health message (National Academies of Sciences, Engineering, and Medicine 2016). Before this can be done, it is imperative to establish an accurate and reliable measure of people's existing levels of knowledge. Fortunately, in recent years a number of studies have been conducted that investigated these factors in defined target populations in Saudi Arabia. Among the recently published studies about drug addiction in Saudi Arabia, is one that aimed to measure the prevalence of drug abuse among athletes (Al Ghobain et al. 2016), which was closely preceded by a study to assess the knowledge and the prevalence of drug use among high school students in Jazan (Siddiqui and Salim 2016). Another study measured the perceptions and prevalence of drug use among medical students in Riyadh (Al-Haqwi 2010).

The current study, tackling the issue of HCPs awareness of drug addiction in Saudi Arabia for the first time, found that the level of knowledge among studied HCPs regarding negative consequences and signs of drug addiction was relatively good. This level improved further after the educational program.

Our study showed that psychological and social disorders were the most commonly known negative health consequences reported by more than ninety percent of HCPs followed by potential involvement in crimes. After the educational program this knowledge increased on average by $10 \%$, compared to an increase of $20 \%$ for knowledge about medical negative health consequences. This may be explained by the difference in knowledge score between the technical and administrative participants $(\mathrm{P}=.03)$, and the fact that psychosocial effects can be easily detected while other negative medical health consequences (cardiovascular, liver, and gastrointestinal) required a specific medical background. Happell, Carta and Pinikahana (2002) also reported an adequate level of knowledge among technical staff about the negative medical outcomes associated with drug use.

Most of the participants in this study ( $>90 \%$ ) recorded good knowledge regarding drug addiction signs and symptoms - in particular physical body signs, behavioral changes, personality changes, and dramatic changes in habits 
and/or priorities. Conversely, there was a low level of awareness (58.22\% and $65.01 \%$ ) among studied HCPs about the existence of a national body (Nebras) and the availability of a free drug addiction hotline to support drug addicts and their families. Encouragingly, the knowledge score improved significantly in both domains after the educational program.

At baseline, there was no statistical difference in knowledge regarding drug addiction among male and female HCPs $(\mathrm{P}=.67)$. Moreover, it is interesting to note that after the educational program, improvement of knowledge regarding drug addiction was found to be higher among female HCPs $(47 \%)$ than male ones (44\%), while improvement of knowledge regarding the national project (Nebras) was found to be higher among male HCPs (57.9\%) than female ones (44.3\%) $(\mathrm{P}<.05)$. One might surmise from this that women were more interested in the theoretical information while men were more interested in practical solutions, proposing taking gender differences into consideration when designing health educational interventions (Al-Khashan et al. 2012).

Unlike previous studies conducted among adolescents (Siddiqui and Salim 2016, Ahmed et al. 2002, Haddad et al. 2010), no significant association was found between age and level of knowledge either for drug addiction or the service provided among HCPs. This discrepancy may be because during mid- to lateadolescence, young people rely more on their peer groups in forming their opinions (Nebhinani et al. 2013, Haddad et al. 2010) and learning new information, as well as being overall more active socially compared to adult HCPs.

Significantly, this is the first national study in Saudi Arabia assessing the knowledge of HCPs regarding drug addiction, setting the ground for future research. The key limitation of this study is the absence of a control group of HCPs that had not been exposed to the educational program. Therefore, the possibility that other factors, not related to the educational programs, could have affected the results, cannot be excluded. Yet, the findings are generalizable to the study's target population.

\section{Recommendations}

Future educational programs may consider using a multi-model approach with an increased focus on the available national services for drug addiction as well as making sure to target all members of the health care team, both medical and non-medical. A valuable area for future research would be assessing the knowledge and attitude of HCPs towards drug addicted patients and what procedures should be followed.

\section{Conclusion}

In general, this study found a good existing level of knowledge among HCPs about drug addiction, and a lower but still fair level of knowledge regarding the availability of national services for drug addicts and their families in Saudi 
Arabia. Although many HCPs lack formal training regarding drug addiction, we have demonstrated that providing them with a short educational intervention can be effective, and we believe that their increased awareness will allow them to recognize the signs and symptoms of drug addiction among patients in their clinics and proactively engage with them to encourage them to find help and thereby directly improve service utilization.

\section{Conflict of Interest}

The authors of this study certify that they have no conflict of interests in the subject matter or materials discussed in this manuscript.

\section{Acknowledgement}

The authors would like to acknowledge the contribution of health practitioners working in Saudi regional Clinical Education Directorates for their help in collecting the needed data. They would also like to acknowledge the contribution of the team member Malak K. Alashaywi (BSc Health Education, General Directorate of Clinical Education, $M O H$ ) who contributed towards the planning and implementation of the health educational program.

\section{References}

Ahmed S, Rana A, Chowdhury S, Mills A, Bennett S (2002) Substance and drug abuse: knowledge, attitude and perception of school going adolescents in Bangladesh. Regional Health Forum 6(2): 59-71.

Al Ghobain M, Konbaz MS, Almassad A, Alsultan A, Al Shubaili M, AlShabanh O (2016) Prevalence, knowledge and attitude of prohibited substances use (doping) among Saudi sport players. Substance Abuse Treatment, Prevention, and Policy 11(1).

Al-Haqwi A (2010) Perception among medical students in Riyadh, Saudi Arabia, regarding alcohol and substance abuse in the community: A cross-sectional survey. Substance Abuse Treatment, Prevention, and Policy 5(2).

Al-Khashan HI, Almulla NA, Galil SA, Rabbulnabi AA, Mishriky AM (2012). Gender differences in health education needs and preferences of Saudis attending Riyadh Military Hospital in the Kingdom of Saudi Arabia. Journal of Family \& Community Medicine 19(3): 172-177.

Cassens, BJ (1992) Preventive Medicine and Public Health. Philadelphia: Lippincott Williams and Wilkins.

National Academies of Sciences, Engineering, and Medicine (2016) Ending Discrimination Against People with Mental and Substance Use Disorders: The Evidence for Stigma Change. Washington, DC: The National Academies Press.

Haddad L, Shotar A, Umlauf M, Al-Zyoud S (2010) Knowledge of Substance Abuse Among High School Students in Jordan. Journal of Transcultural Nursing 21(2): 143-150. 
Happell B, Carta B, Pinikahana J (2002) Nurses' knowledge, attitudes and beliefs regarding substance use: A questionnaire survey. Nursing and Health Sciences 4(4): 193-200.

McBride N (2003) A systematic review of school drug education. Health Education Research 18(6): 729-742.

National Center for Narcotics Control (2018) Markaz istisharat al-idman [Addiction Consultation Center]. Retrieved from https://ncnc.sa/1955-2/.

Nebhinani N, Nebhinani M, Misra AK, Grewal S (2013) Substance-Related Knowledge and Attitude in School and College Students. German Journal of Psychiatry 16(1): 15-19.

Siddiqui AF, Salim AM (2016) Awareness of substance use and its associated factors in young Saudi students. Journal of Medical \& Allied Science 6(2): 61-67.

US Department of Health and Human Services, Office of the Surgeon General (2016) Facing Addiction in America: The Surgeon General's Report on Alcohol, Drugs, and Health. Washington, DC: HHS.

Wallace R, Kohatsu N (2007) Maxey-Rosenau-Last Public Health and Preventive Medicine $\left(15^{\text {th }}\right.$ ed.). Stamford, Connecticut: Appleton \& Lange.

World Health Organization (2010) ATLAS on substance use (2010): Resources for the prevention and treatment of substance use disorders. Switzerland, Geneva: WHO Press.

Wright JD, Pearl L (2000) Experience and knowledge of young people regarding illicit drug use, 1969-99. Addiction 95(8): 1225-1235. 